\title{
4,5 месяца от идеи микромодуля до готового образца
}

\author{
Проект НПЦ СЭС и ОКБ Пятое Поколение, \\ представленный на выставке ExpoElectronica 2019
}

\section{В. Мейлицев}

\section{В рамках деловой программы выставки ExpoElectronica}

АО “НПЦ СпецЭлектронСистемы" (НПЦ СЭС) провел семинар «Возможности 3D-интеграции в микросборках нового поколения на основе низкотемпературной керамики LTCC", в ходе которого были представлены результаты совместного проекта НПЦ СЭС и ОКБ Пятое Поколение по разработке микромодуля цифрового изолятора на основе низкотемпературной совместно спекаемой керамики (LTCC). 3а 4,5 мес. компаниям удалось разработать конструкцию микромодуля, отработать техпроцесс его изготовления и выпустить опытный образец, готовый к испытаниям.
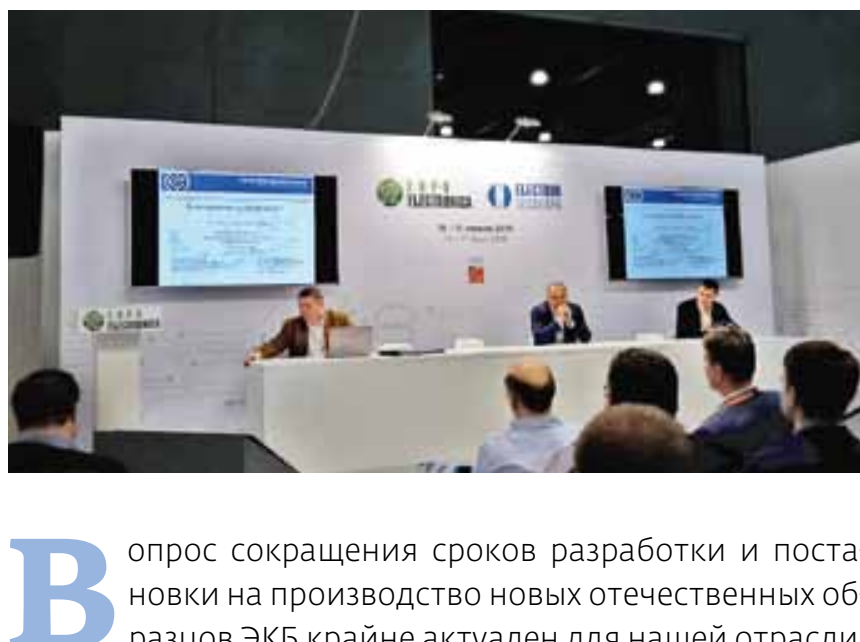

опрос сокращения сроков разработки и постановки на производство новых отечественных образцов ЭКБ крайне актуален для нашей отрасли. Решение этой задачи было одной из основных целей создания в 2018 году НПЦ СЭС нового производственного комплекса по изготовлению изделий на основе LTCC, о возможностях которого вкратце рассказал в начале семинара С. А. Михайлов, исполнительный директор АО «НПЦ СпецЭлектронСистемы». В частности, он отметил, что, помимо трехмерных керамических модулей, многокристальных микросборок и специализированных корпусов, основные виды продукции комплекса включают пассивные компоненты СВЧ-электроники, многослойные керамические платы и другие изделия на основе LTCC. Кроме того, для заказчика может выполняться корпусирование различных изделий, таких как датчики, МЭМС ит.п.

Реализация совместного с ОКБ Пятое Поколение проекта по созданию модуля гальванической развязки среднечастотного цифрового сигнала - цифрового изолятора (ЦИ) подтвердила эффективность концепции, положенной в основу производственного комплекса. Все работы от начала проектирования корпуса до выхода готовых образцов на испытания удалось завершить за 4,5 мес., из которых около 2 мес. заняло конструирование корпуса, а остальное время - собственно процесс отработки технологии. Обычно на выполнение проектов подобной сложности требуется не меньше 6 мес.

Схемотехническая часть ЦИ к началу проекта уже была разработана специалистами ОКБ Пятое Поколение и проверена на экспериментальном прототипе в стандартном металлокерамическом корпусе (рис. 1). Результаты электрических испытаний показали соответствие основных электрических параметров расчетным значениям. Об этом в рамках своего доклада сообщил руководитель проектов компании В. А. Бутузов.

Конструкция корпуса для полнофункционального прототипа микросборки ЦИ (рис. 2) была разработана партнерами проекта совместно, а технологическую отработку процесса изготовления выполнил НПЦ СЭС. Об этом более подробно рассказал директор по производству АО «НПЦ СпецЭлектронСистемы» В. А. Косевской.

Конструктивно модуль ЦИ представляет собой микросборку на основе трех кремниевых кристаллов: приемника, передатчика и развязывающего трансформатора. Первые два кристалла выполнены по КМОП-технологии с проектной нормой 0,18 мкм с использованием методов 


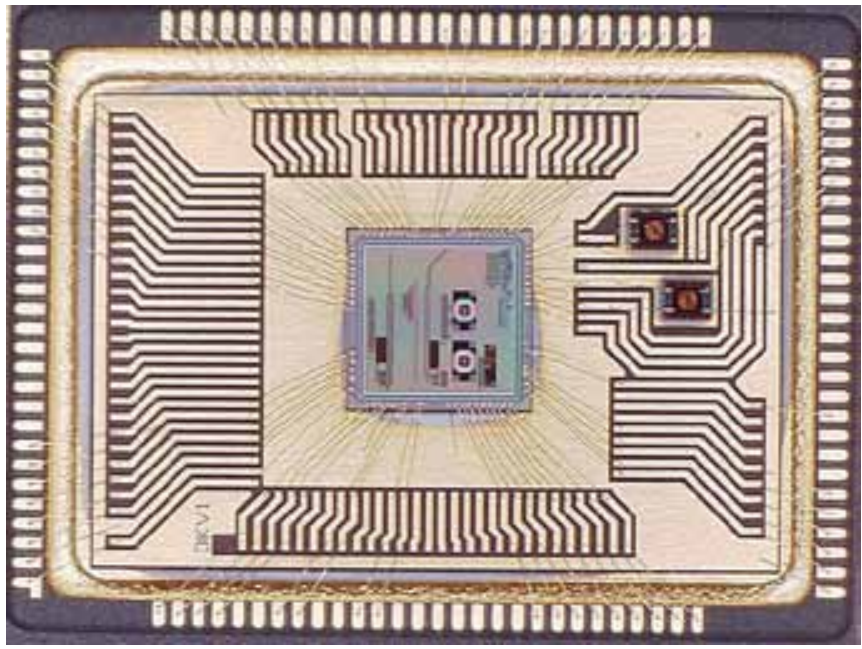

Рис. 1. Экспериментальный прототип ЦИ - микросборка в корпусе MK 4233.112-А - по электрическим характеристикам идентичен штатному образцу, но имеет отличия по составу кристаллов

повышения стойкости к ионизирующему излучению. Развязывающий трансформатор (рис. 3) построен по схеме расположения обмоток, в которой на каждом из слоев металлизации размещаются фрагменты первичной и вторичной обмоток, вложенные друг в друга. Так достигается минимизация его размеров и снижение уровня потерь. Трансформатор изготовлен по интегральной технологии с проектной нормой 90 нм. Слои металлизации разделены диэлектриком на основе оксида кремния.

Коммутационная структура, обеспечивающая межсоединения кристаллов между собой и с внешними выводами модуля, реализована в многослойном основании герметичного корпуса из низкотемпературной керамики. При

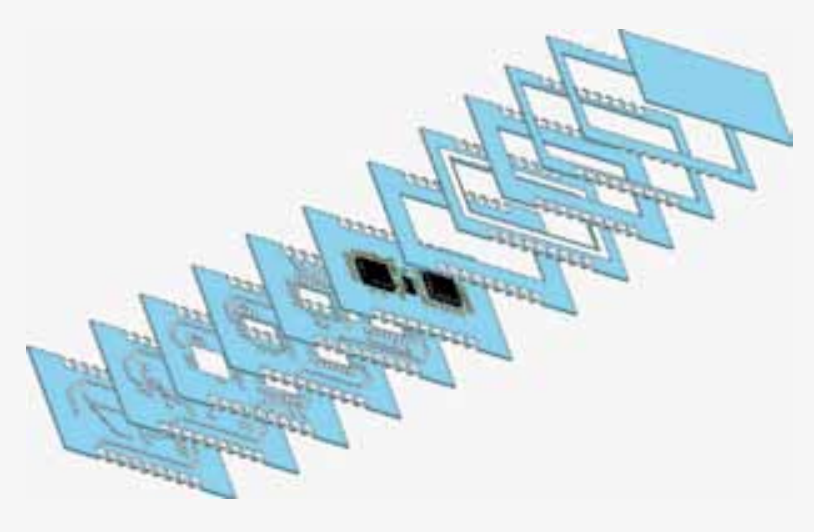

Рис. 2. Послойная структура модуля цифрового изолятора этом кристаллы имеют неодинаковую толщину, а частоты, на которых они работают, делают критичной длину внутренних проводников и предъявляют высокие требования в части минимизации паразитных связей. В ходе отработки технологии изготовления корпуса микросборки был, в частности, подобран режим прессования пакета керамических листов с предназначенными для посадки кристаллов колодцами различной глубины и большим отношением глубины к горизонтальным размерам, а также режимы герметизации в инертной среде (азоте) и в вакууме корпуса с керамической крышкой.

В проекте использована система материалов низкотемпературной керамики компании Dupont, разварка соединений производилась золотой проволокой диаметром 25 мкм по методу "шарик-клин". В данной модификации прототипа применено клеевое соединение кристаллов с керамикой; в рамках изучения вопроса долговременной надежности отрабатывается вариант монтажа на пайку.

Решение о разработке для ЦИ специального корпуса на основе LTCC, давшее старт проекту, было обосновано целым рядом получаемых при этом преимуществ. В рамках традиционного, до сих пор превалирующего в отечественной электронике подхода кристаллы пришлось бы ставить на промежуточную монтажную плату, например, из кремния, в которой были бы реализованы внутренние связи между кристаллами, а входные и выходные цепи выводились бы на ее контактные площадки, которые, в свою очередь, соединялись бы с контактными площадками корпуса и через них с выводами микросборки. Под всю собранную на промежуточной плате конструкцию был бы подобран ближайший по размеру стандартный корпус, который, очевидно, был бы значительно крупнее специально разработанного.

Применение корпуса из LTCC дает возможность организовать все необходимые связи в многослойной структуре его основания. Это позволяет существенно уменьшить габариты и массу устройства, а также сократить длину электрических связей как между кристаллами, так

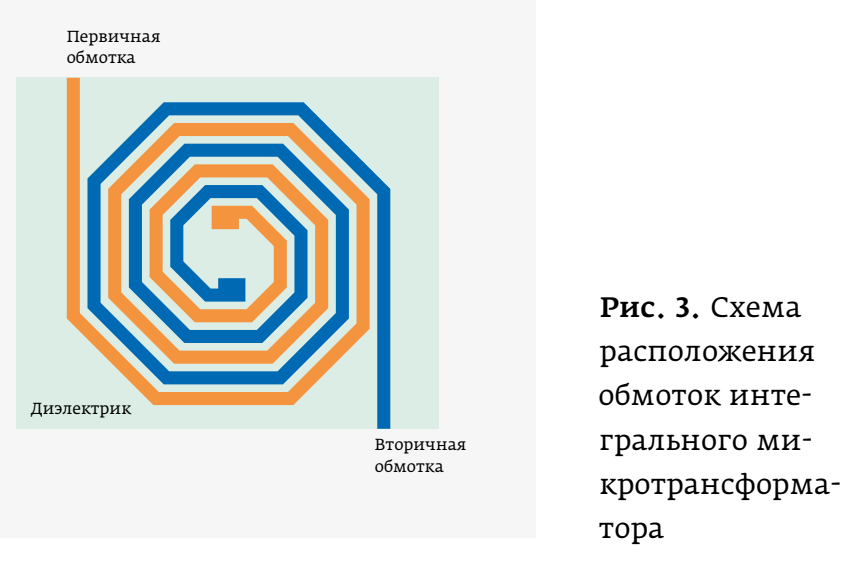


a)

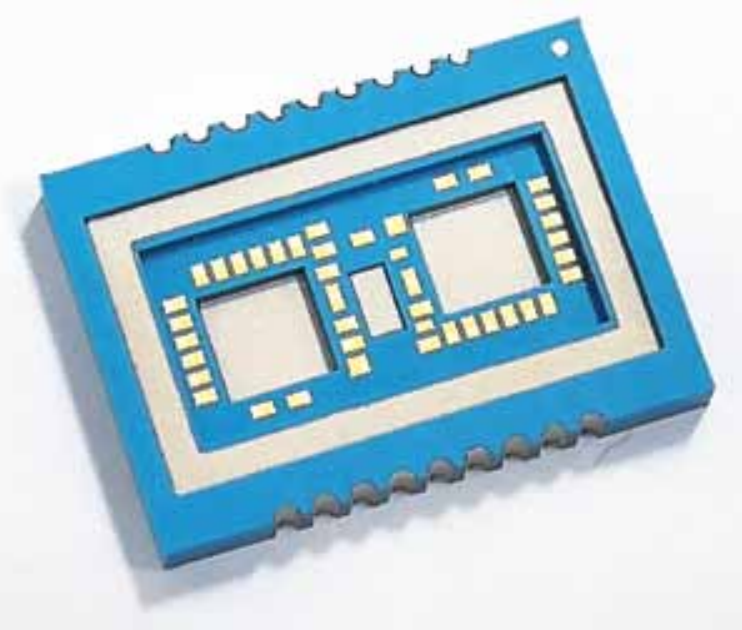

б)

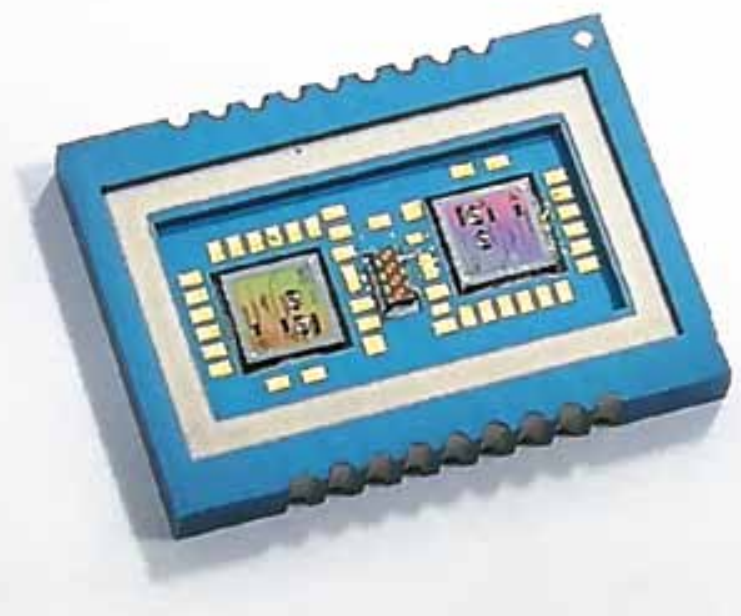

B)

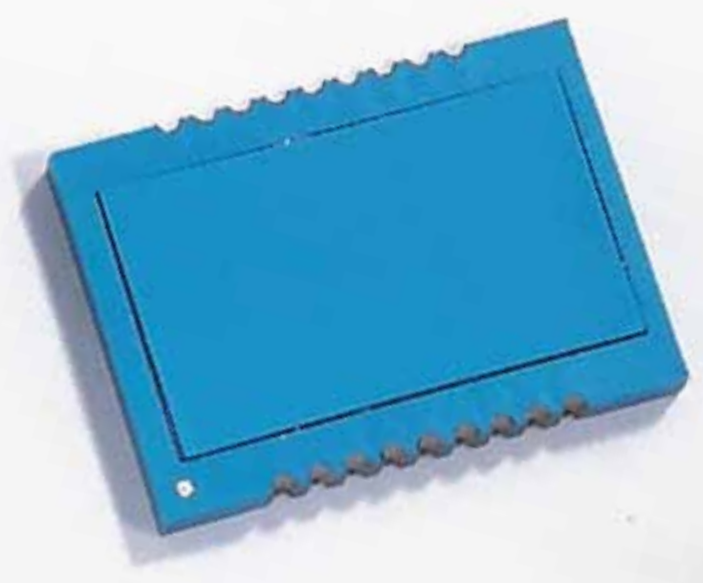

Рис. 4. Модуль цифрового изолятора: а - корпус до монтажа кристаллов; 6 - микросборка перед герметизацией; в - полностью собранный модуль и между ними и выводами корпуса. Также уменьшается количество выполняемых соединений. Так, при традиционном подходе потребовалось бы выполнять соединения между кристаллом и промежуточной платой, а затем - между промежуточной платой и контактными площадками выводов корпуса; в примененной технологии необходим лишь первый вид соединений, поскольку основание LTCC-модуля само несет коммутационную функцию промежуточной платы, а связь с выводами корпуса реализована непосредственно в нем. Сокращению длины связей и количества соединений внутри модуля способствует и возможность установки кристаллов заподлицо с основанием путем выполнения колодцев для их посадки, чем достигается оптимизация разварки проволочных соединений. Уменьшение длины проводников и их количества снижает вероятность образования паразитных связей, а разработчик имеет возможность предотвращать их появление, используя ресурс многослойности коммутационной структуры корпуса микросборки. Кроме того, меньшее количество соединений способствует повышению надежности модуля.

Еще одна группа преимуществ обусловлена физическими свойствами материалов, входящих в систему LTCC. Температурный коэффициент расширения (ТKР) низкотемпературной керамики очень близок к ТКР кремния, что делает механическое соединение кристаллов с корпусом практически нечувствительным к термоциклированию. Проводники, получаемые при обжиге из золотоили серебросодержащей пасты, имеют в несколько раз меньшее удельное сопротивление, чем проводники на основе вольфрама и молибдена, характерные для высокотемпературной керамики, - это важный параметр для любого электронного устройства, а для устройства, работающего на высоких частотах, - в особенности. Примененная в конструкции ЦИ керамическая крышка корпуса, в отличие от металлической, не может спровоцировать электрический пробой между проводником и корпусом, что позволяет минимизировать высоту конструкции и избавляет от обязательного расчета зазора между ней и токонесущими элементами и жесткого контроля величины и равномерности этого зазора в процессе герметизации изделия.

Кроме того, конструкции из LTCC способны выдерживать значительные механические нагрузки, работать при температурах до $350^{\circ} \mathrm{C}$ и обладают почти нулевым влагопоглощением.

B. A. Косевской обратил внимание на то, что в LTCC-технологии ряд механических и электрических характеристик определяется производителем материалов, что позволяет при наличии отработанныхтиповых техпроцессов заранее прогнозировать данные параметры конечного изделия. При этом в задачи испытаний входит лишь подтвердить достижение заданных свойств. Благодаря этому 
возможно существенное сокращение сроков разработки и запуска в серийное производство новых изделий.

Готовый полнофункциональный прототип цифрового изолятора представляет собой изделие с габаритами небольшой микросхемы: 13,4×18,4×2,31 мм (рис. 4). Одним из основных видов механических испытаний, в значительной степени определяющим общий успех при отработке технологии микросборок для жестких условий эксплуатации, является проверка на герметичность при термоциклировании. На данный момент испытаниями была подтверждена способность модулей сохранять требуемый уровень герметичности после 100 циклов в температурном диапазоне от -65 до $150{ }^{\circ} \mathrm{C}$ (скорость натекания 6,6·10-8 мбар·л/с). Планируется проведение испытаний с более жесткими условиями: 20 термоударов в термошоковой камере с диапазоном температур от -196 до $150^{\circ} \mathrm{C}$.

Гибкость, присущая технологии LTCC, позволяет развивать разнообразные проекты, в том числе нетривиальные. В докладе В. А. Косевского было уделено внимание исследовательской работе, ведущейся в настоящее время специалистами НПЦ СЭС в инициативном порядке, в ходе которой изучается возможность управления теплоотводом.

Теплоотведение - традиционная задача для микроэлектроники, и обычно она решается за счет теплопроводности подложки, через которую требуется отвести максимум тепла на внешние элементы конструкции прибора. Инженеры НПЦ СЭС прорабатывают другой подход - они пробуют контролируемо формировать тепловые поля. Для этого в многослойных LTCC-структурах создаются специальные "тепловые столбы» - отверстия определенной формы и дислокации, заполненные серебросодержащей пастой, по которым осуществляется перераспределение тепла от нагретых зон в соответствии с заданной конфигурацией теплового поля.

Интересно отметить, что при таком подходе очевидно низкая по сравнению с металлами теплопроводность керамики часто становится не недостатком, а необходимым качеством, предопределяющим саму возможность организации целенаправленного движения тепловых потоков

Измерения, проведенные с изготовленными для исследования образцами изделий в режиме холостого хода и под нагрузкой, показали стабильность сформированных тепловых полей и незначительные отличия локальных температур от расчетных значений. Представляется, что результаты этой работы и знания, накопленные в ее ходе, могут стать основой эффективного технического решения проблемы теплоотвода в микроэлектронных устройствах.

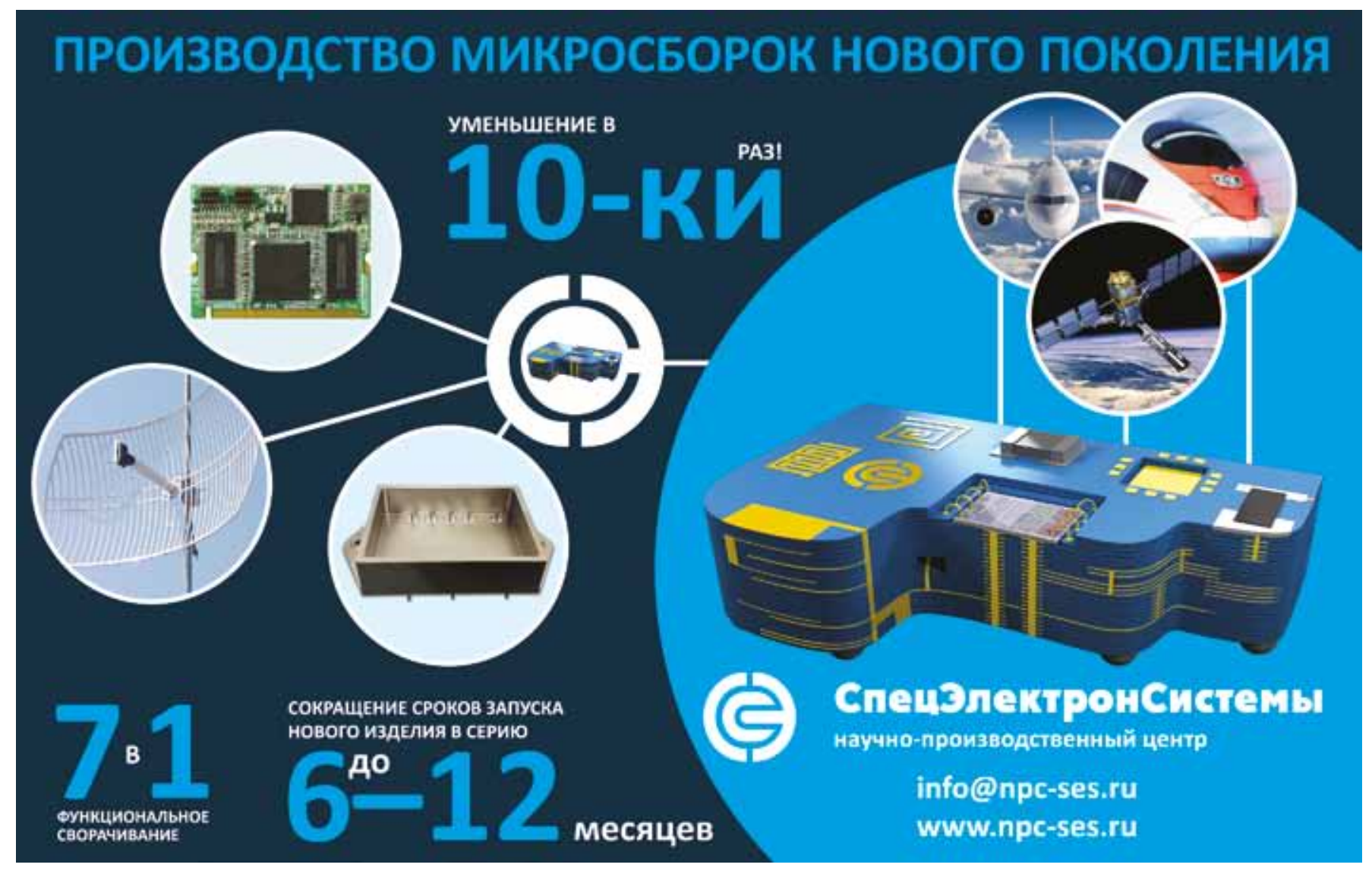


В заключительной части семинара о рыночных перспективах подобных разработок рассказал заместитель директора по развитию АО «НПЦ СпецЭлектронСистемы» А. В. Вагин. Трехмерные микромодули на основе технологии LTCC могут быть с успехом применены в изделиях для таких перспективных рынков, как автомобильная электроника, телекоммуникации 5G, Интернет вещей, для различных датчиков, в том числе для биосенсорики, и во многих других областях.

Как правило, такие задачи не могут выполняться силами отдельной компании. Для создания полноценных решений нужны разработчики, конструкторы, программисты, которые будут работать в связке между собой. Поэтому А. В.Вагин подчеркнул, что
АО «НПЦ СпецЭлектронСистемы» очень заинтересовано в сотрудничестве, в совместной работе с дизайнцентрами, в том, чтобы реализовывать различные идеи, которые возникают у участников рынка.

Представленный на семинаре проект как раз является примером того, как успешно могут взаимодействовать компании. Создание в сотрудничестве двух компаний готового к испытаниям изделия в столь короткие сроки является прецедентом, показывающим возможность достижения реальных результатов, который необходимо масштабировать для реализации системных проектов в отечественной электронной и радиоэлектронной отрасли.

\section{КНИГИ ИЗДАТЕЛЬСТВА «ТЕХНОСФЕРА»}

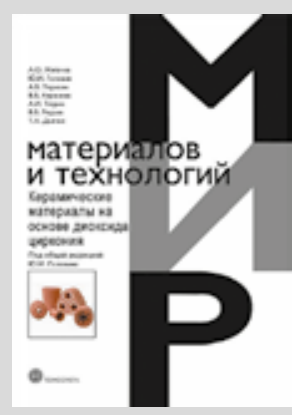

Цена 760 руб.

\section{КЕРАМИЧЕСКИЕ МАТЕРИАЛЫ HA ОСНОВЕ}

\section{ДИОКСИДА ЦИРКОНИЯ}

\author{
Жигачев А. О., Головин Ю. И., Умрихин А. В.,
} Коренков В. В., Тюрин А. И., Родаев В. В., Дьячек Т. А. Под общей редакцией Ю. И. Головина

В книге обобщены данные по возможному химическому составу, кристаллической и микроструктуре, а также свойствам керамических материалов на основе диоксида циркония. Рассмотрены наиболее развитые технологии получения этих керамик и композитов на их основе. Монография состоит из четырех частей, каждая из которых освещает определенную область вопросов, связанных с керамическими материалами.

Книга будет интересна широкому кругу читателей: от студентов естественно-научных специальностей до инженеров, технологов и медицинских работников, связанных с практическим применением циркониевой керамики.

Разработка методов синтеза, получение и подготовка оригинальных керамических образцов на основе бадделеита выполнены при поддержке гранта Российского научного фонда (проект № 16-19-10405). Отработка методик исследования и определение физико-механических характеристик осуществлены при поддержке гранта Министерства образования и науки Российской Федерации (проект № 16.2100.2017/П4). 


\section{МОСКВА, ВДНХ, ПАВИЛЬОН №75 \\ 22-25 ОКТЯБРя 2019}

XXIII МЕЖДУНАРОДНАЯ ВЫСТАВКА
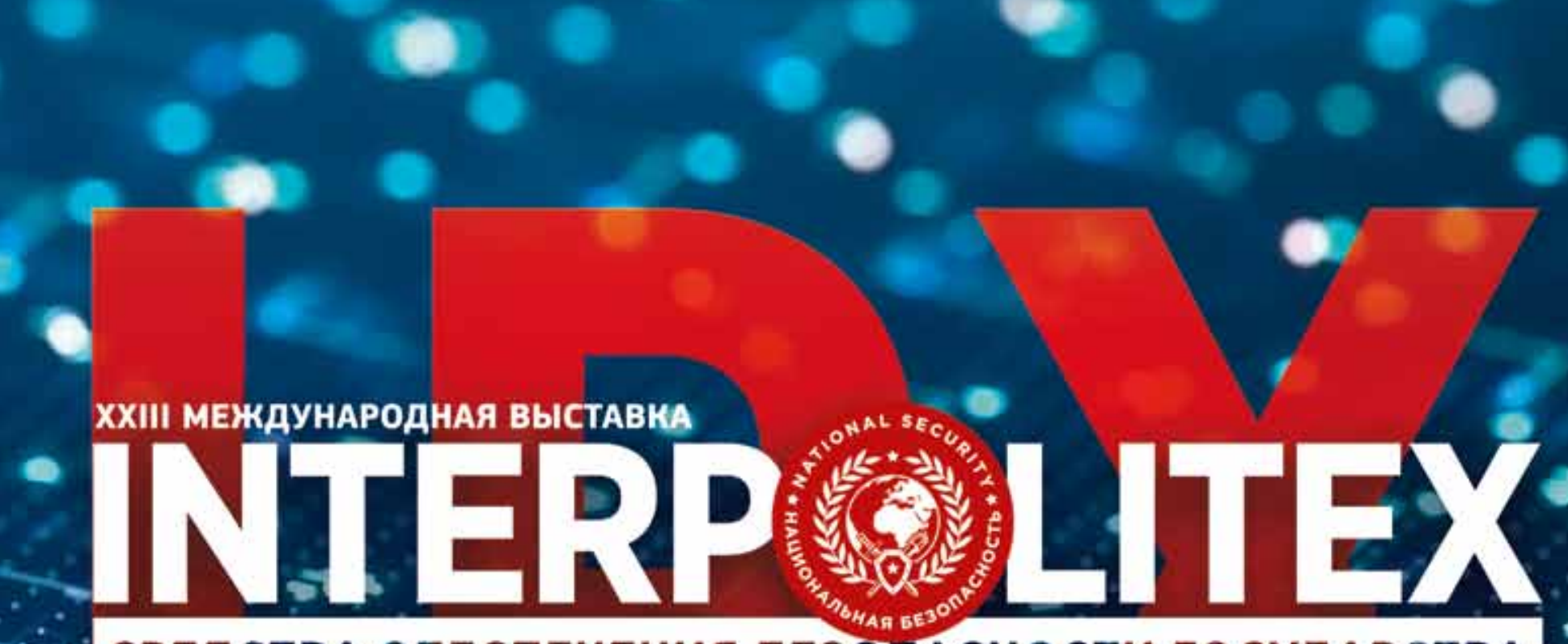

\section{СРЕДСТВА ОБЕСПЕЧЕНИЯ БЕЗОПАСНОСТИ ГОСУДАРСТВА}

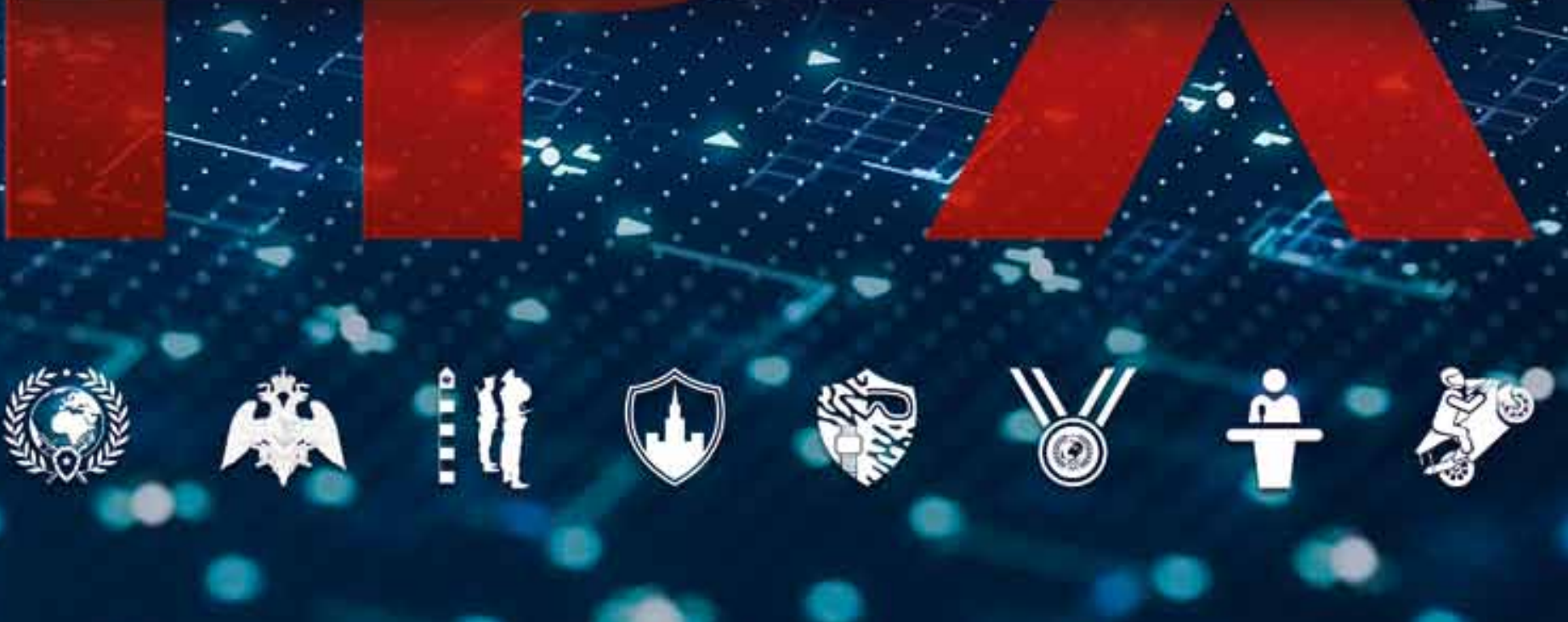

\section{WWW.INTERPOLITEX.RU}

OРГАНИЗАТОРЫ

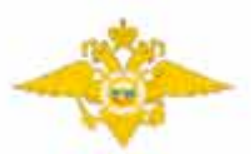

мвд России

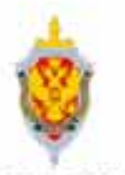

ФСБ РОССИИ

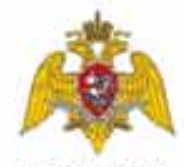

РОСТВАРДИЯ
OPTAHИЗАTOP ВЫСТАВКИ КГРАНИLА

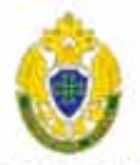

ПС ФСБ РОССи
ЭКСПОНЕНТ-КООРДИНАТОР ОТ МВД РОССИИ

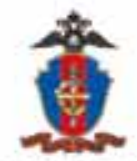

ФКУ \&HกO \&CTИC. МВД РОССИИ
REHEPANЬHЫЙ
УСТРОИTЕ

IForher

$3 A O=O B K=5 И 3 O H *$ 